\title{
Critical Policy Analysis: Staring into Space
}

\author{
Robert A. Doherty \\ School of Education University of Glasgow \\ Email: Robert.Doherty@glasgow.ac.uk
}

\begin{abstract}
This paper engages with the relation between what could be characterised as an upsurge in interest around spatial theory across the social sciences and education policy research. A limited review of spatial theory is developed by way of illustrating the ontological and epistemological multiplicity within theorisations of space and place. While eschewing forms of theoretical spatial exuberance, the limited but productive attention to spatial theory in critical policy research is discussed. The paper concludes by attempting to develop a number of possibilities, lines of investigation, in looking towards space and the spatial within critical education policy analysis. In particular, spatial aspects of policy theory, policy discourse and policy at the level of implementation are explored.
\end{abstract}

Keywords: Space, spatial theory, education policy

How we represent space and time in theory matters, because it affects how we and others, interpret and then act with respect to the world. (Harvey 1990, 205)

\section{Introduction}

Policy annunciates what is to be done. Policy seeks to orchestrate the symbolic, to write a legitimating score for the courses of action it demands. Policy builds, establishes and rests on a normative account, an assumptive world. Public policy is heterogeneous in its sponsoring authority, the magnitude and scale of its directive detail and in the degree of sanction attached to deviation or non-compliance. Whatever can be said about the nature of policy, it has won its place in the modern art of government as a yet unsurpassed instrument of direction, control and regulation. It is within the nature of this efficacy that the power of policy can be recognised. Moreover, behind or masked within this most ubiquitous device of modern rule rests an exercise of human will.

It is around a commitment to understanding education policy within an 'economy of power' (Ball 1994), inseparable and indivisible from the politics and power relations of the social order over which it is projected, that critical policy analysis has developed and coalesced. This paper offers some reflections on, and appraisal of, space and the spatial within critical policy analysis in the context of a wider engagement with the spatial across the disciplinary boundaries of social science. One way to understand any spatial 'turn' would be in terms of the migration and utilization of ideas and conceptual resources produced within recognised disciplinary boundaries (principally geography and in particularly human geography). It is in such contexts that working answers to fundamental questions about space have been developed and employed to support forms of empirical work and theory building. This paper engages with the question of the extent to which critical policy analysis, as an area of research, has profited from the extension of spatial theory. In particular it responds to a recurring call, by authors who have engaged with frameworks and conceptual resources drawn from the theoretical grammar of spatial thought, that there is as yet more productive use to be made of space. A short and illustrative review of the variance and diversity of epistemological and ontological commitments to be found in the current cannon of spatial literature is provided. In addition, the paper looks to make a small contribution to the context described above by offering what could be termed nascent possibilities, lines of investigation, in looking towards space and the spatial within critical policy analysis.

The language of social theory has long been enriched by borrowings from and across other fields and disciplines. Silber (1995) points to the natural sciences, biology, genetics, physics and to other sectors of social science, economics, psychology, as well as metaphors borrowed from areas of the humanities such as history, music and theatre. Education and public policy apart, there has been something of a turn to 
space in social theory's recent past. One manifestation of this has been the growing prevalence of spatial metaphors and orientational references in the explanations of social science as the language of theory has incorporated the spatial, quasi-geographical in order to augment and sharpen its conceptual lexicon. Illusions to 'vertical,' 'horizontal,' 'fields,' 'boundaries,' 'turns,' and many varieties of 'spaces' are now familiar and seemed to have earned their salience by merit of a certain form of lucidity. Silber (ibid) usefully differentiates between strong and weak spatial metaphors, distinguished by the degree of prominence given to the metaphor and its centrality in carrying the theoretical accounts being developed. Another noteworthy dimension to the turn to space in social theory is the operation of spatial constructs in perhaps four relations to space and the spatial. Ordinary language is one form and source of reference to spatial constructs and metaphors. The theoretical language of social science is not immune to, or hermetically sealed off from, the conventions of ordinary language or 'commonsense.' Secondly, projects of social enquiry and theory building are also centred on or concerned with the relation of 'absolute space' or 'Euclidean space,' to other aspects of social life. This is space as inscribed in cartography or transversed by satellite navigation. In this enterprise the language and constructs of space are unavoidably present in the theoretical articulation of explanations for a whole range of social relations and patterns. A third form can be composed from abstractions, representations, impressions, perceptions of space, overlapping with a whole gamut of concerns over attachment, feeling and the fundamentality of space in human consciousness; together with their relation to other aspects of the social order. A fourth type of instance of spatial metaphors and language is the conscious use of such referents in the conceptualisation and theorisation of other aspects of the social order understood as not connected to absolute space or physical topology. Spatial theory within the social sciences can be further complicated by the interaction and coexistence of two or more forms of spatial reference within the same theoretical expositions.

\section{$2 \quad$ Thinking with Space}

In looking to the emergence of spatial theory as a means to extend or reinvigorate the resources of critical policy analysis a note of caution needs to be sounded. The beguiling expressiveness and attraction of spatial ideas and references can tempt a shallow and convenient engagement. An unexamined adoption of conceptions of the spatial harbours the danger of forgoing a necessary level of conceptual rigor. In looking to harvest the critical potential of spatial theory in the service of a critical reading of policy, and policy making, a discerning engagement with the spatial cannon becomes a prerequisite. In this sense, the builders of new and hybrid analytical frames need to answer the question posed by Smith (2004) 'why space?' There is also an important and obvious prior question to any claim for the salience of the spatial in illuminating a multitude of social differences and political arenas; what is to be understood by space, place or the spatial?

The development and exercise of theories of place, space and spatiality are central to the field of human geography. This field of intellectual activity combines geography with perspectives and research issues found across the social sciences. Even though 'absolute space' or 'Euclidean space,' is, in a sense, indispensable to geography, the focus of human geography is not on the material landscape, the physical topology, but rather on a whole multiplicity of geographical patterns and relations connected to human activity. Human geographers have pursued interests in areas such as patterns of economic concentration, health, urbanism, communications, and technology. It is perhaps unsurprising that human geographers have led the way in exploring the spatial dimensions of education ${ }^{1}$; both methodologically and in terms of its conceptualisation.

\footnotetext{
${ }^{1}$ One notable area of research that combines education, geography and computer software is the use of Geographical Information Systems (GIS) (Parsons, Chalkley \& Jones, 1996). This sector of research combines attention to absolute space and techniques of cartography with a range of educational issues including; school catchments areas and zones, parental choice and marketization, educational outcomes and neighbourhood effects (Taylor, 2001). The use of postcodes as locating devices beyond mail delivery has been a significant aspect of this development. This has provided a means of locating pupils and analyzing spatial patterns using GSI.
} 
Within the field of geography Cresswell (2004) sketches a genealogy of meanings attached to 'place,' that extends across the ideographic, the social constructionist, and the phenomenological. The ideographic, characteristic of regional geographers, is essentially descriptive, looking to establish and record places and regions in terms of differences, uniqueness or distinctiveness. This approach to knowledge of place and the spatial is long established and tends to define geography in the popular imagination. This detailed description would extend from geology, climate and biodiversity to regional cultures. Cultures (and their many dimensions; areas of presence, history, ecology) would inspire a school of cultural geography. Place and space provide the terra firma on which cultures coagulate, take root and are sustained. Culture is a medium that structures conduct and shapes agency. Subjects are both fashioned by such cultural densities and possess the capacity to navigate between them, transversing and coexisting within multiple codes and patterns. Cresswell (ibid.) notes a scientific turn in human geography in the 1970s with the discipline shifting from the centrality of the ideographic towards a kind of spatial mathematics. Another feature of spatial science was its lack of interest in the presence or location of humans. This school abandoned regionality in favour of a science of space; a search for laws and generalisations with place being relegated to an uncomplicated location in space.

The development of a humanistic geography can be understood in part as a response to the scientific turn. In stark contrast, this tradition conceived of place and places as deeply significant and intimately connected to the experience of being human. Place and being in place are understood as foundational to human existence. Edmund Husserl's phenomenology was the foremost philosophical perspective taken up by humanistic geographers, expressed in a search and concern for the essence of place and its significance in human consciousness. The work of Heidegger (Heidegger, Macquarrie and Robinson,1967) has influenced humanistic geographers committed to the profound significance of place in human experience and consciousness. This social constructionist perspective places the emphasis on place and space as shaped, established and changed through social processes. Such processes of construction, change and dissolution are animated by relations of power in the social order. Notably from the stance of critical policy analysis, all of the three approaches above, and their combinations, attach differing meanings to place and the spatial and champion different forms of knowledge of place and space.

No consideration of contemporary spatial theory would be remotely comprehensive without consideration of the important impetus to the theorisation of place and space arising from the work of Marxist thinkers of various hues. The classic writing of Engels on the reshaping of the urban under industrial capitalism, The Condition of the Working Class in England in 1844, is an early contribution. The establishment and spread of industrial capitalism fashioned the very landscape of modernity; urbanising, altering places, spatial relations, linkages and flows with a novel violence, speed and intensity. Significant in the cannon of spatial literature is the work of French Marxist social theorist Henri Lefebvre (1901-1991). In the later part of his life, and after his death, the reading and rereading of his innovative work on space has provided a stimulus to its theorisation across a whole range of disciplines including urban theory, architecture, politics, sociology and in particular human geography.

In his early work Lefebvre was engaged by the relation and transformation of the town and country; the rural and the intensification of the urban. The Marxist idea of 'production,' drawing on early Marx, is given a much wider application in the theorisation of space by Lefebvre. Capitalism may constitute new relations in terms of economic production, but this structuring dynamic also produces institutions, knowledge and even society. Production is not only material, it also alters consciousness. Lefebvre is significant for pushing the abstraction of space beyond Euclidean space, to include the significance of other forms of space that operate in everyday life, implicating the social production of space as a dimension of the dominance exercised by a hegemonic class (Elden 2004). In the context of a historical mode of production every society produces a certain structure of spatialization. In his most renowned spatial text, The Production of Space (Lefebvre 1991) Lefebvre describes different modes of the production of space; including 'absolute space,' (natural space), and what he called 'social space' a more abstract and complex scheme of spatiality. For Lefebvre the meanings and importance attached to social space are socially produced. Lefebvre analysed social space in terms of a spatial triad; perceptions and common practices, how space is represented, or abstracted, and through what he understood as the contemporary spatial imaginary; taking the idea of imaginary from neo-Marxist psychoanalysis.

Following Lefebvre, Soja has elaborated what he called a trialectics of spatiality (1989). Natural, real or Euclidean space, the space of cartography and inscription, empirically measurable space, is posited as 'firstspace.' Secondspace comprised of representations, impressions, perception of space, overlapping with 
the whole gamut of humanist concerns over attachment, feeling and the fundamentality of space in human consciousness. The final dimension of Soja's trialectic model is 'thirdspace.' This is lived space and 'it interrupts a distinction between perceived space and spatial practices' (Cresswell 2004, 38). Thirdspace is located between the materiality of natural space and consciousness, the representation of space. Thirdspace is a form of spatialization that operates in the everyday, the lived, is evident in the practices and the performances that constitute the social world.

David Harvey is arguably the most influential contemporary philosopher of geography and his writings on the nature of space and place under capitalism are unwaveringly political; obvious in such texts as Social Justice and the City (1973) and Justice, Nature and the Geography of Difference (1996). Harvey (2006) has consistently worked across and articulated a 'tripartite' categorization of spatial theory. This matrix is comprised of formulations of absolute, relative and relational space. Absolute space is measurable, gridable, the space of land mapping, navigation, and property deeds; it is the space of Euclidian geometry and Newtonian mechanics. The concept of relative space is modern and proceeds in two senses; recognising the multiplicity of geometries available to quantify relative space and the question of perspective. Einstein has become synonymous with the idea of relativity, one example being if two observers are in relative motion events that are simultaneous for one observer, may not be simultaneous for the other. Under relativity the relation between space and time shifts to space-time, spatio-temporality and the idea of simultaneity has to be abandoned. For Harvey many spatial realities are elucidated through relative space (time), this would include the spatio-temporal patterns of commodity circulation, finance, people and energy.

Perhaps one of the most current theoretical deployments of relative space is in explanations of globalization around the idea of the compression of space by time and more critically, uneven geographical development (Harvey 2006). The premodern is characterised in one aspect as being tied to place, disconnected by distance, in contrast to the modern or high modernity as characterised by mobility, connectivity, or increasing connectedness where distant events have increasingly local and more immediate impacts. Harvey gives the example of cloth production in Mexico no longer being viable at a time and in a particular absolute space because of 'conditions of labour in China when mediated through exchange processes in relative space time that transforms value as a social relation' (Harvey 2006, 144). Despite its short comings (Harvey 1990), Hagerstrand's (1975) time geography, with its unambiguous space-time dimensions, has stimulated and influenced the engagement of social theory with space (see Giddens 1984).

Relational space is perhaps the most abstract of the three types of spatial theory; its philosophical roots are associated with the thought of the German polymath Gottfried Wilhelm Leibniz (1646-1716). Leibniz took the view that space and time were not real objects themselves. From this perspective space consisted of the relations between objects, rejecting an absolutist position, and arguing that what is understood by space and time could only be discerned within the spatial frame internal to the processes that define them. As an activist geographer Harvey $(2006,125)$ cites the example of Tiananmen Square or Ground Zero; in looking for meaning in such places he concludes that, 'the only way I can seek an answer is to think in relational terms.' In theorising space and time, in the study of different phenomena, Harvey works from the principle of keeping the three approaches, absolute, relative and relational, in dialectical tension.

So is space (space-time) absolute, relative or relational? I simply don't know whether there is an ontological answer to that question. In my own work I think of it as being all three. This was the conclusion I reached thirty years ago and I have found no particular reason (nor heard any arguments) to make me change my mind. (Harvey, 2006, 125)

Within sociology there has been a renewed interest in space, typified in the emerging literature around the term 'spatial inequality' (Lobao, Hooks \& Tickamyer, 2007). This thematic has drawn together, within a spatial framing, work on areas such politics, poverty, prosperity, mortality, ethnic migration, urban landscapes and power. The centrality of space, place and spatiality to schools of academic geography has been articulated with a range of investigations and projects of enquiry that recognise space as a fundamental dimension of human societies. Robertson (2010), for example, has attempted to enrich the sociology of education by endeavouring to apply critical spatial framings in generating new investigative standpoints. The recognition of spatiality, place and space as a universal and inescapable component of the social order situates it as an unavoidable field of engagement; an illuminating constituent of the dynamics and structuring of forms of society. Space is posited as an explanatory 
dimension that elucidates or makes visible a whole range of motivating concerns, problems and areas of enquiry. Such engagements with space may follow from investigations of 'equality' or 'culture' or 'justice' as the first order concern. This subsequent looking to the spatial as part of a wider project of enquiry requires in turn an integrating engagement with the theorisation of space and place.

Notably, Foucault in his analysis of the development of the disciplinary society primarily identifies space, absolute and relative space, within techniques of surveillance, discipline and normalisation. In Discipline and Punish $(1977,141)$ he asserts that 'in the first instance, discipline proceeds from the distribution of individuals in space.' From the perspective of an analytics of governmentality (Foucault, 2007), space and place emerge as an indispensable component within the construction of regimes of government. Conduct is conduct in place, within borders or boundaries; in the exercise of political sovereignty government is territorial. Through a host of spatial aspects (understood through a myriad of abstractions from absolute space to social space) governmental reason seeks to intervene, to regulate and condition. For Rose $(1999,35)$ the territorial aspect of governmental reason draws attention to those 'spaces of enclosure that governmental thought has imagined and penetrated: schools, factories, hospitals, asylums, museums, now even shopping malls, airports and department stores.' Central to the field of critical policy analysis is the conviction that public policy constitutes one of the primary means of governmental intervention.

\section{$3 \quad$ Finding Space in Critical Policy Analysis}

Attempts to apply ideas and perspectives on space and place to the field of education policy analysis seem vulnerable to a kind of blunting obscurantism. Even the short and superficial consideration of the literature around theories of space and place above serves to underline its many voices that together produce a beguiling polyphony of abstractions. This demands effort be applied to the task of separating and setting out both concepts and their relation; articulating a working position upon which to build any policy analysis and striving in the process to avoid what Ball (2006) has described as 'sloppy interpretative work.' Such an ontological positioning must make some attempt to explicate the form and limitations in which conceptions of space and place operate within any perspective employed to bring order to any task of critical analysis.

Policy, in the service of governmental action, has an inescapable spatial dimension to its nature. Nonetheless, it is notable across the critical policy literature ${ }^{2}$ that the spatial turn is detectable as more of a deflection. Claims such as Gulson's $(2005,142)$ to have developed an 'explicitly spatial form of policy analysis' are uncommon. Arguably, this is not due to proponents of critical policy analysis having somehow 'missed the turn.' Rather it is more likely to be as a consequence of the early utilization and promotion of those aspects of the spatial with an evident and productive application in the work of analysis (see for example: Ball, Bowe and Gewirtz 1995, Ball, Maguire, and Macrae 1998, 2000, Taylor, 200, 1Gulson 2005, 2008, Lingard, 2007 and Peters \& Kessl 2009). Rather than a conceptual languor on the part of critical policy readers, the ideas and language of the spatial have not presented as capable of displacing, in the theoretical imagination, a range of established and productive ideas enabling the critical reading of policy.

Having noted the as yet modest influence of spatial theory is there more to be gained from looking into space? While resisting the promotion of spatial theory as a dramatic paradigm altering innovation, or fashionable conceptual accessory, there would as yet seem to be untapped potential for the enrichment or elaboration of the working conceptual frames of policy analysis. Gulson and Symes (2007, 13) have promoted the idea of spatial theory acting as 'a catalyst, providing possibilities for disruption, and a demonstration of the potential directions within, and for, educational policy studies.' Policy is rarely, if ever, innocent; married as it is to the exercise of institutionalised power. Place and space in a range of guises emerge as a policy concern. If critical policy perspectives have become established around an assumption that policy is ultimately an exercise of political power and that the language of policy is

\footnotetext{
${ }^{2}$ In a search across three leading education policy journals the number of papers identified as dependent on a form of spatial theory in the conceptualisation of the research, beyond space as a simple flexible metaphor, barely reached double figures.
} 
ideological in its character, it follows that representations of place and spatial organisation in policy reflect or mobilise the structures, concerns and beliefs present in the dominant order of power relations.

Place and space within policy can be recognised as operating in three interrelated dynamic aspects; the discursive, the material and a third 'lived' aspect, what Soja (1996) constructs as thirdspace. From this stand point, there is an order of discourse which makes place, space, and the spatial, thinkable, imaginable, knowable, endowing it with a salience that corresponds to and orders forms of experience. The second dimension arises from the universality of the materiality of place together with corporality; with its physical limitations and restrictions in absolute space. The lived aspect of space and place is an attempt to make meaning in the complex boundary between materiality, identity and subjectivity, with its regimes of signification and the significance of the everyday. Essential actors can conceive of place and space, which is elemental to consciousness. Actors are also creatures of place and space, identifying and attaching meaning to place, living and moving in space, physically burdened by the 'friction of distance.'

Spatial knowledges, or some form of surrogate, present as a universal in human societies. Policy discourses can be read with a concern for how they draw upon or work to establish, construct and assert a regime of meaning in relation to place, places and the spatial. Such discourses are forged from an amalgamation of representations and discourse types drawn from the wider order of knowledge of the spatial. Place and space can be engaged in ways that converge with the ideographic mode of the geographer but more; place and the spatial become a central surface of action, an unavoidably stark dimension of the modern that materially bears its weight and, in every sense, its imprint and flows. Place and spacing, the organisation of space, shifts and alters to reveal the complexities, conflicts and dynamics of the society of late modernity. This is the production of space; how place and space are abstracted, defined and redefined, appropriated, allocated, projected and normalised. For a critical policy analysis, how place and the spatial are authoritively established, represented and altered within policy presents an observatory on the exercise of this form of power. An array of the 'courses of action' encoded into policy are interventions on or in space, place or what are assumed to be homogenous forms of place, and the practices they enfold, be it the estate, the community, the area of deprivation, the school, the classroom, the area of priority treatment, the action zone, the city academy or the most deprived neighbourhoods.

Question: What should be the main characteristics of new Action Zones if they are to achieve the objective of motivating young people in tough inner city areas? (Excellence in Schools, DfEE 1997, 40)

Policy is territorial, inseparable from the creation of governable spaces. It follows that the narratives and texts of public policy unavoidably contain representations of the spatial. The presence or ascendancy of such spatial discourses can perhaps be categorised into two comprehensible forms. Policy as an exercise of political power, as a course of action, must have a location of application, a 'where,' a relation to place. Many policy texts operate with an assumed or unspoken domain or spatial range of application. The governable spaces assumed in policy may vary in scale, (national, regional, local or particular) or in the conception of the application of policy across dispersed networks of places assumed to contain an institutional homogeneity to their order and activity. The presence of territorialization, the landscape of places and spaces addressed in policy, is often submerged, present as a subtext, reflecting the assumptive worlds and culturally grounded imagination of policy makers.

A second and overt form of spatial discourse operates in policy texts that set out courses of action concerned with organizing, dividing, and authoritively establishing governable spaces. Policy that constructs catchment areas, districts for the local administration of education, together with policy that works to establish, open or close borders and boundaries, manifest a clear spatial aspect. The inescapability of place and the spatial to the intelligibility of state reason requires a myriad of courses of governmental action be encoded into policy incorporating a spatial constituent as part of their logic and claims for coherence. Policy concepts such as education action zones, areas of priority treatment or a neighbourhood renewal agenda, depend on a dividing and establishment of spaces in governmental reason.

This focus on the operation of place and space in policy centres around the exercise of power in constructing spaces and places as part of a mandated and ideologically inflected course of action. It focuses on the government of zones, areas and places through policy. It places attention on the authoritative representation of place and space, its discursive establishment, and its implantation into forms of subjectivity and regimes of self regulation. This attention to spatial discourse, what Gulson 
describes in terms of a 'poststructural spatial analytic' (2007, 46), has the capacity to open up or reveal the fabrication of spaces, the assimilation and mobilisation of spatial knowledges and the transactions of a politics of space.

It is at the level of policy implementation and operation, where texts and policy imperatives are translated into actions and performed in deeds and practices in the life world (social space or thirdspace); attention to space and place emerge as another productive sector for critical policy analysis. The institutional context of public policy is intercostaled by a proliferation of policy imperatives. Policy in operation or enactment takes place on a stage that is intersected and crossed by other performances heavy with struggles, resistances, desires and demands. Spatiality and place, at the level of policy implementation and operation comes into view as significant to an understanding of who gets what from education. The structure of society, its formal and informal social, economic, and political institutions, including education, incorporates a spatial ordering. Under the capitalism of late modernity, space (absolute, relational, relative) is produced and reproduced, textured and woven into patterns that reveal a multitude of oppressions, distributions and concentrations of socially desirable goods. The fundamentality of place and space to human existence renders it revelatory to the condition of social justice. Even for a critical policy analysis inclined to a post-structural conception of discourse there is a need, following Parsons $(1995,73)$, to bootstrap ${ }^{3}$ and work within the rules, the 'regimes of truth,' that measure, quantify or inscribe space.

The numbers, metrics and coordinates that make place, Euclidean or relative space intelligible also can inscribe, or map onto, the existence and location of a host of material and social realities that structure human flourishing; identity, ethnicity, gender, memories and histories, poverty, deprivation, housing, transport and crime. Much of the observation, mapping and inscribing of what is to be found in grided space has had its origin in the academy and in responses to social dilemmas and degradations. Knowledges of place and space provide critical metrics with which to plumb the society of late modernity. Space in its many dimensions that dissect education can be correlated to numerous explanatory elements: class, ethnicity, gender, access, disaffection, distribution, outcomes, flows, conflicts and social reproduction.

By contrast with relatively small regional differences, in all of the outcomes we examine, from education at 16 to equivalent net incomes, there are profound differences at neighbourhood level, between those with higher and lower levels of deprivation. Even allowing for the way in which average levels of qualifications, employment and incomes form part of the indices used to establish which are the most and least disadvantaged areas, the differences between them were some of the most striking... (Hills, et al. 2010, 248)

There is a fabricated nature to the spaces in which the practises, iterative behaviours, rituals and scripts that make social structure visible are enacted. Here it is possible to begin to consider the integration of a philosophy of everyday life (Heller 1984) or those dimensions of the human condition that Marxists approach through alienation and, in particular, iterative practices across space-time (Giddens 1984), with conceptions of policy as an apparatus of power. Policy seeks to intervene, to act on, to direct, the recurrent practices that recreate and substantiate in space-time those aspects of the social order we understand as institutions and recognise by the functions around which they coalesce. In offering an account of the constitution of society, or more precisely a theory of 'structuration' that attempts to reconcile structure and agency as a duality, Giddens (ibid.) provides an instance of the conceptual resources that can be built upon in looking to explore further the spatial in policy theory.

Policy as the direction of action, as the delineator of values and allocator of resources, looks to impose its order on a matrix of iterative practices and the subjectivities that make them intelligible and interpretable. The assertion of will encoded into policy as text assumes to exert its power over action, recursive actions, in space-time. Public policy has a locus of application in absolute space, and is

\footnotetext{
${ }^{3}$ In physics Geoffrey Chew argued that theoretical physicists should simultaneously hold on to a range of partially successful theoretical models, resisting partiality, in recognition that the complexity of the universe is such that no one theory can begin to capture it. He called this approach bootstrapping; attempting to work across and take from a range of models. In terms of perspectives on policy analysis, Parsons (1995) argues that this analogy is applicable to policy analysis; the complexity of policy in late modernity necessitates an interdisciplinary approach and a hermeneutic openness to different perspectives.
} 
substantiated by its iterative recreation in space-time or relative space and is laid open to meaning making by its conceptualisation in relational space. The interplay between policy in place, absolute space, policy as seeking to direct actions in what are imagined to be homogeneous or institutionally replicated spaces, and policy as enacted and performed through repetitive practices in relative space, and the frames of subjectivity that make them intelligible, draw attention to policy in substantiating and directing the spaces of the everyday.

Perhaps it is possible to conceptualise the efficacy of policy in directing action, asserting values and commanding resources in absolute space and in space-time, working from and between two poles of coded imperatives. Policy can attempt to prescribe the fine grain of practices, and concomitant regimes of justification and intelligibility, that are to be iterated in the actions of knowledgeable actors. Policy can also seek to authoritively set down the ends of action, to establish terminal goals and destinations. This form of direction is intent on leaving latitude for knowledgeable agents to use, alter and transmutate recurrent regularised practices in space-time in the pursuit of what has been authoritively positioned as essential ends. Policy can be conceived as contributing to the weave of a social structure that is both constraining and enabling.

\section{Conclusions}

Space may be understood as having a multiplicitous nature; possessive of an ungovernable dimension to its character. The possibility and human capacity to seek out and create what Foucault (1971) conceived as heterotopias must also be acknowledged. Notwithstanding, the efficacy of policy as a regulator of practices and a technology of direction, while far from a totalising form of power or domination, can be understood as a structuring element in the production and ordering of space. Human beings are creatures of space and place; corporality, memory, identity, belonging and affective attachment (topophilea) draw attention to the centrality of space and place to human existence. This universality of place and space position them as a reoccurring thematic and motif in political narratives and ideological schemes. Political power has a history that records its projection over space, between borders, its tendency to seek to enlarge its territorialization (habitually looking to extend its reach over new zones, spheres of influence and national backyards). For Cresswell (2004, 12), 'place, at a basic level, is space invested with meaning in the context of power.' Projects of government must be capable of abstracting place and the spatial; defining, dividing, allocating and changing the material topology together with the iterative practices, identities, roles and symbolic regimes associated with places and units of space. The spaces and the spacing of the hospital, asylum, jobcentre, counselling unit, administrative site, factory, barracks, data hub, policing district, street, highway, the housing estate and school, and the practices they enclose, are constructed, in the context of power, out of the tensioned interplay between social structures, the material and the discursive.

Forms of spatial knowledge, in particular those that have come to inform a critical human geography, would seem to offer a number of critically productive conceptual frames from which to extend or sharpen projects of analysis and to inform explanations of policy across all its stages and consequences. Place and geography have become mainstream and indispensible in the analysis and evaluation of policy implementation and in answering important questions over policy outcomes and consequences.

Many dimensions of social justice (access, distribution, reproduction) are rendered visible, often with a demanding starkness, thrown open to observation through absolute and relative spatial framings. It could be suggested that relational space in the explanation of social phenomena has become established within critical human geography as a way to draw upon and integrate other explanatory perspectives from out with its own boundaries in its pursuit of questions common across social science. In terms of critical policy analysis, relational space, as a perspective or standpoint, would seem to have many able contenders in offering analytical purchase. This may go some way to accounting for its rare deployment so far in the policy literature.

There would as yet seem to be latent potential in further attention and interpretative sensitivity being applied to decoding the spatial regimes of truth present in policy discourse. Concomitantly, the interpretive resources employed to critically analyse and explain forms of policy discourse can be further supplemented by the incorporation of spatial theory. There is a challenge to theorise, in a productive way, the influence of policy in the iterative practices of the everyday and in the constitution of the 
symbolic economy of space and place that influences 'how we and others, interpret and then act with respect to the world' (Harvey 1990, 205). The fundamentality of the spatial in all its forms holds an attraction for the critical imagination. Policy is heavily implicated in the fabrication of the many dimensions that consubstantiate lived spaces. In a sense public policy acts to create and sustain spaces; furthermore the significance of policy is indispensible to the regimes that govern them. This spatial attraction perhaps reflects a sense of the elemental nature of space, an instinctive understanding and seeking out of relations that connect policy to the spatial. However, it is important to avoid what Robertson (2010) calls the fetishization of space. While endeavouring to keep a realistic assessment of the capacity of spatial theory to open up new lines of enquiry for education policy analysis, the possibilities of space would seem far from exhausted.

\section{References}

1. Ball Stephen, J. (1994). Education reform: a critical and post structural approach. Buckingham: Open University Press.

2. Ball Stephen, J. (2006). Education Policy and Social Class. The selected works of Stephen J. Ball. Abingdon, Oxon: Routledge.

3. Ball, S. J., Bowe, R., \& Gerwitz, S. (1995). Circuits of schooling: a sociological exploration of parental choice in social class contexts. Sociological Review, 43, 52-78.

4. Ball, S., J., Maguire, M., \& Macrae, S. (1998). 'Race,' space and the further education market place. Race, Ethnicity and Education, 1 (2), 171-189.

5. Ball, S., J., Maguire, M., \& Macrae, S. (2000). Space, work and the 'new urban economies'. Journal of Youth Studies 3 (3), 279-300.

6. Cresswell, T. (2004). Place: a short introduction. Malden, MA: Blackwell Pub.

7. DfEE. (1997). Excellence in Schools. HMSO

8. Elden, S. (2004). Understanding Henri Lefebvre: theory and the possible. London: Continuum.

9. Engels, F. (1844). The Condition of the Working Class in England. Oxford: Oxford University Press.

10.Foucault, M. (1971). The Order of Things. New York: Vintage Books.

11.Foucault, M. (1977). Discipline and punish: the birth of the prison. London: Allen Lane.

12.Foucault, M. (2007). Security, territory, population. Basingstoke: Palgrave Macmillan.

13.Giddens, A. (1984). The constitution of society: introduction of the theory of structuration. Berkeley: University of California Press.

14.Gulson, K. N. (2005). Renovating educational identities: policy, space and urban renewal. Journal of education policy, 20(2), 141-158.

15.Gulson, K. N. (2007). Mobilizing space discourses: Politics and educational policy change. In K. N. Gulson \& C. Symes (Eds.), Spatial theories of education: policy and geography matters (pp. x, 287 p.). London: Routledge.

16.Gulson, K. N. (2008). Urban accommodations: policy, education and a politics of place. Journal of education policy, 23(2), 153-163.

17.Gulson, K. N., \& Symes, C. (2007). Spatial theories of education: policy and geography matters. London: Routledge.

18.Hagerstrand, T. (1975). Survival and arena: on the life history of individuals in relation to their geographical environment. In T. Carlstein, Parkes, D., Thrift, M. (Ed.), Human Activity and Time Geography. London: Wiley \& Sons.

19.Harvey, D. (1996). Justice, Nature and the Geography of Difference. Cambridge: Blackwell.

20.Harvey, D. (1973). Social Justice and the City London: Hodder \& Stoughton.

21.Harvey, D. (1990). The condition of postmodernity: An enquiry into the conditions of cultural change. Cambridge MA \& Oxford UK: Blackwell.

22.Harvey, D. (2006). Spaces of global capitalism. London: Verso.

23.Heidegger, M., Macquarrie, J., \& Robinson, E. S. (1967). Being and time. Translated by John Macquarrie \& Edward Robinson. (Reprinted.): Oxford: Blackwell.

24.Heller, Agnes. 1984. Everyday Life. London: Routledge \& Kegan Paul. 
25.Hills, J., Brewer, M., Jenkins, S., Lister, R., Lupton, R., Machin, S., Riddell, S. (2010). An anatomy of economic inequality in the UK. Report of the National Equality Panel. . London: CASE/LSE.

26.Labao, L., Hooks, G., \& Tickamyer, A. (Eds.). (2007). The sociology of spatial inequality. New York: State University of New York Press.

27.Lefebvre, H. (1991). The production of space. Oxford: Basil Blackwell.

28.Lingard, B. (2007). Deparochializing the study of education. In K. N. Gulson \& C. Symes (Eds.), Spatial theories of education: policy and geography matters (pp. 233-250). London: Routledge.

29.Parsons, J. M., Chalkley, B., \& Jones, A. (1996). The role of Geographic Information Systems in the study of parental choice and secondary school catchments. Evaluation and Research in Education, 10(1), 23-34.

30.Parsons, W. (1995). Public Policy. Cheltenham: Edward Elgar.

31.Peters, M., \& Kessl, F. (2009). Space, Time, History: the reassertion of space in social theory. Policy Futures in Education, 7(1).

32.Robertson, S. L. (2010). Spatializing'the sociology of education. The Routledge international handbook of the sociology of education: Oxon: Routledge 15-26.

33.Rose, N. (1999). Powers of freedom: reframing political thought. Cambridge: Cambridge University Press.

34.Silber, I. (1995). Space, Fields, Boundaries: The rise of spatial metaphors in contemporary sociological theory. Social Research, 62(2), 323-355.

35.Smith, N., 2004. Space and substance in geography. In Cloke, P., Crang, P. and Goodwin, M. (Eds.). Envisioning human geographies, pp11-29, London: Arnald.

36.Soja, E. W. (1989). Postmodern geographies: the reassertion of space in critical social theory. London; New York: Verso.

37.Soja, E. W. (1996). Thirdspace. Malden (Mass.): Blackwell.

38.Taylor, C. M. 2001. Hierarchies and 'Local' Markets: the Geography of the 'Lived' Market Place in Secondary Education Provision. Journal of Education Policy 16(3), pp. 197-214. 